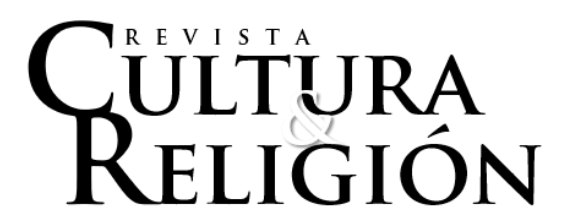

Vol. XIV, Nº 1 (2020) pp. 13-25

Recibido: 10 de enero, 2019

Aceptado: 26 de noviembre, 2019

\title{
ESTÉTICA DE LA ALEGRÍA DEL SACRIFICIO. ANACRONISMO DE LA MODERNIDAD*
}

\author{
Aesthetics of the joy of sacrifice. Anachronism of modernity
}

\author{
Juan Granados Valdéz*** \\ Universidad Autónoma de Querétaro (UAQ) \\ juan.granados@uaq.mx
}

\begin{abstract}
Resumen
En este artículo, su autor propone reflexionar, desde una perspectiva estética, sobre el carácter alegre del sacrificio en clave cristiana, más específicamente, católica. La elección de esta disciplina filosófica estriba en que esta integra las capacidades del ser humano sin disociarlas y porque la experiencia del sacrificio, además de ser religiosa, es estética: al sentirla, puede descubrirse su sentido o su belleza. Tras acotar el sentido del sacrificio, haciendo los respectivos deslindes conceptuales, plantea las diferencias y las similitudes entre el sacrificio antiguo y el sacrificio nuevo -el de Cristo- para, a partir de esto, relevar que el sacrificio es siempre una celebración de la vida y que, por tanto, es alegre, como lo muestra la misa. Entre las consecuencias implicadas, se apunta aquí que la modernidad no hace anacrónicas las prácticas religiosas, tales como la peregrinación, sino que, a la inversa, estas más bien muestran que los adelantos que enorgullecen a la sociedad civilizada, lucen anacrónicos porque están fuera de lugar y de tiempo, del lugar y del tiempo de la fiesta. Mientras la peregrinación celebra la vida, goza y se alegra de la existencia, la civilización apuntala con fuerza su ser absurdo.
\end{abstract}

Palabras clave: sacrificio, alegría, sagrado, estética, modernidad.

\footnotetext{
* Este artículo forma parte de los proyectos de investigación: "La prudencia como modelo de interpretación para la estética" (FBA-2017) y "Símbolo, simbolismo y simbolistas. Estudio sobre la naturaleza y el sentido simbólico de las artes para la filosofía y la religión desde el movimiento simbolista" (FBA-2019).

${ }^{* *}$ Licenciado en Filosofía y maestro en Arte Contemporáneo y Sociedad, Universidad Autónoma de Querétaro (Querétaro, México). Doctor en Artes, Universidad de Guanajuato (Guanajuato, México). https://orcid.org/0000-0003-4020-9055
} 


\begin{abstract}
In this article, the author proposes the need to reflect, from an aesthetic perspective, on the joyous nature of sacrifice from a Christian viewpoint, and specifically from a Catholic perspective. The choice of this philosophical discipline is that it integrates the capabilities of the human being without dissociating them. Furthermore, the experience of sacrifice, in addition to being religious, is aesthetic: when you feel it, you can discover its meaning or its beauty. After discussing the meaning of sacrifice, and providing the respective conceptual demarcations, the author sets out the differences and similarities between ancient sacrifice and new sacrifice - that of Christ - to reveal that sacrifice is always a celebration of life and is therefore joyous, as demonstrated by the Catholic Mass. Among the implied consequences, it is shown here that modernity has not made religious practices anachronistic, such as the pilgrimage. Conversely, it has rather revealed that the progress that fills civilized society with pride, appear more anachronistic as they are out of place and time, that is to say the place and time of celebration. While pilgrimage celebrates life, and revels in and rejoices existence, civilization strongly asserts its absurdity.
\end{abstract}

Keywords: sacrifice, joy, sacred, aesthetics, modernity.

\title{
Introducción
}

El interés reciente por temas religiosos, especialmente por el tema del sacrificio, puede encontrarse en la publicación de obras tanto modernas como contemporáneas, de distintas áreas del conocimiento y de distintas latitudes: en Francia (Jean-Luc Nancy, René Girard), en México (Antonio Arvizu, Rogelio Téllez). Sin embargo, la enumeración de libros y artículos sobre el tema resulta inabarcable. Pese a esto, lo que se busca destacar aquí es la ausencia de apreciación de un cierto carácter estético propio del sacrificio, a saber, la alegría. ¿La alegría del sacrificio? El título parece encerrar un contrasentido. ¿Qué de alegre tiene llevar uno a cabo? Nada de alegre tiene, por ejemplo, si se entiende como la matanza de personas en la guerra, o como el peligro grave que corre alguien, o como la sujeción con dolor o repugnancia de alguien a una acción a la que es sometido por la moda o la dieta o como la matanza de animales de y para el consumo humano. El sacrificio, no obstante, no solo tiene estos sentidos seculares. Para su mejor comprensión, se impone otra vía de acercamiento, la religiosa, más específicamente la católica, que rescata la alegría implícita, a veces tácita, en él. Este acercamiento se propone desde la estética o desde una perspectiva estética.

Pero ¿qué es la estética o a qué me refiero con perspectiva estética? Se entiende por estética a la rama de la filosofía que se aboca al estudio de la (propia) sensibilidad (Arvizu, 2005; Beuchot, 2012), base de la experiencia y el juicio estéticos, y que, orientada por el intelecto, es el aparato con el que se capta la belleza. La estética es, entonces y en primer lugar, filosofía de la sensibilidad y filosofía de la belleza. Pero la estética conecta con las artes, ya que estas son objeto de la belleza y motivan especialmente la sensibilidad. Así pues, la estética, en segundo lugar, es filosofía del arte. Esta arista estudia las condiciones de la creación artística y la recepción de las artes. Como puede verse, el recurso iterativo de la estética comienza con la sensibilidad y con ella acaba. El estudio del gusto, pues, resulta del tratamiento de lo anterior (Beuchot, 2012; Blanco, 2007). Una cosa más es menester decir. Puesto que la sensibilidad es el aparato de aprehensión o captación de la belleza y el arte, ha de señalarse qué supone. La sensibilidad se desdobla en la percepción, el entendimiento, las 
emociones o sentimientos y la imaginación (Beuchot, 2012). Así pues, la aprehensión del fenómeno del sacrificio y su carácter alegre se lleva a cabo por la sensibilidad o, mejor dicho, pasa por la percepción sensorial, va a la imaginación, se vive o siente y, por último, aunque no exactamente en este orden, se entiende o comprende.

A esta definición o descripción y sus detalles es importante mencionar que hay dos caminos de acceso a la estética, a saber: uno ascendente y otro descendente. El primero va de los hechos a las ideas, de lo particular a lo general, de la práctica a la teoría. Es el camino de la inducción. El segundo sería el de la deducción, que va de lo general a lo particular, de la teoría a la práctica. La estética se mueve entre ambos caminos, aunque, por ser, primeramente, saber de la sensibilidad, sea más fácil el ascendente, por paradójico que suene (Blanco, 2007). El primer camino es el que se ha seguido aquí, pues de la experiencia particular, la de un creyente, el autor de este texto se ha avanzado hasta las ideas que se expresan en este trabajo.

La alegría es un sentimiento de placer o satisfacción que orienta el ánimo y se expresa mediante la risa o la sonrisa. Hacer una estética de la alegría, pero no en cualquier situación, sino de la del sacrificio, me parece no encierra ningún contrasentido, sino que aclara cuándo, verdaderamente, se está frente a algo que, como se dice hoy en ciertos contextos de habla hispana, llena. La etimología de satisfacer es muy reveladora. Es eso que resulta bastante, es decir, cumple con las expectativas. La corrupción de las cosas o su carácter temporal jamás podrá cumplir con lo que el ser humano necesita, solo lo eterno. Así lo vieron los pensadores cristianos, desde la Escolástica medieval hasta nuestros días. Por eso pienso que la alegría (gaudium) se encuentra en lo que conecta, como el sacrificio, con lo eterno. Una estética de la alegría del sacrificio exploraría la manera en la que se vive o experimenta el sacrificio, pero como algo que resulta alegre, tanto porque de suyo invita a la alegría como porque, como se dijo, llama a alegrarse.

En lo que sigue, desde la perspectiva de un creyente, que también es la de un filósofo que intenta un acercamiento estético, se reflexionará y analizará el sacrificio, después de acotar el sentido del término, haciendo los respectivos deslindes conceptuales y enunciando el planteamiento de las diferencias y las similitudes entre el sacrificio antiguo y el sacrificio nuevo, el de Cristo, para hacer notar que el sacrificio es siempre una celebración de la vida y que, por tanto, es alegre. Todo esto solo es posible desde un tratamiento o acercamiento estético. Sin embargo, se admite que las convicciones de quien esto escribe se involucran. La experiencia, desde la infancia, de peregrinar y ofrecer, es decir, de hacer sacrificios, los estudios teológicos y de filosofía de la religión, junto con la docencia en instituciones religiosas, están en la base de esta reflexión que plantea la alegría del sacrificio y el anacronismo de la modernidad en tiempos de fiesta. Para aclarar aún más, la metodología aquí adoptada es cualitativa, descriptiva. Se acerca a la fenomenología, en este sentido, y a la hermenéutica en la medida en la que se interpreta el sacrificio contextualizándolo.

\section{El sacrificio antiguo y el sacrificio nuevo}

Con matices propios de cultura a cultura, el sacrificio tiene rasgos comunes. $\mathrm{Si}$ atendemos a su etimología, proviene del latín sacrum facere, que significa "volver sagrada alguna cosa". Constatamos que es cercano a consagrar, "hacer sagrado algo dedicándoselo a Dios" (Deiss, 1989, p. 89), y supone introducir algo profano en el área de lo sagrado con el fin de fortalecer el vínculo del hombre con la divinidad (Sahagún Lucas, 1999). 
Dada esta definición, el sacrificio puede darse de tres formas. Puede ser, en primer lugar, un ofrecimiento de dones, también llamado holocausto (del hebreo olah que significa "subir"). En este, la víctima (toro, cabrito, cordero, tórtola o paloma) sube al altar donde se quema enteramente, subiendo a Dios convertida en humo. Simboliza el carácter irrevocable y la totalidad del don ofrecido. En la tradición judaica, el oferente con gesto solemne impone la mano para indicar que le pertenece la víctima. El holocausto expresaba acción de gracias, petición, intercambio y expiación.

Puede ser, en segundo lugar, un sacrificio de expiación. Con él se reconoce la ofensa o culpa, la necesidad de reparar esta y el medio para hacerlo. La expiación se logra mediante el derramamiento de sangre y la destrucción de la víctima, que sustituye a quien sacrifica (Sahagún Lucas, 1999). En las religiones asirio-babilónicas aparece por primera vez el principio de sustitución del sacrificio de expiación en la inmolación de una víctima para entregarla a los demonios que atormentaban a un pecador o un enfermo (Deiss, 1989).

En estos dos primeros casos, la definición de sacrificio como introducción de algo profano en el área de lo sagrado para fortalecer el lazo entre hombre y Dios se aclara por la ofrenda, la petición y la solicitud de expiación. Nada de alegre, empero, se encuentra por ahora. La vida es alegre, su negación no puede serlo. El sacrificio es la negación de la vida de la víctima a la que se le vuelve nada consumida por el fuego en el altar. La negación, no obstante, de la vida de la víctima en el sacrificio es la afirmación de la vida del victimario y de la víctima misma. No podría negársele la vida sin reconocérsela previa y posteriormente. Porque para negar la vida es necesario que la haya antes y porque la vida que ya no lo es como lo era, lo es ahora en otro sentido. Esto se explica a partir del acto de comer. La negación de lo que nos llevamos a la boca no se pierde en la nada indeterminada, sino en una nada determinada que no es eso que se come, es decir, nosotros. Lo que deja de ser lo que es comienza a ser lo que no es, vida para el que lo come. Lo mismo sucede con el sacrificio. En este, la negación de la vida no es sino reconocimiento y afirmación de la vida y de quien depende la vida, de Dios. Y si es así, el sacrificio es alegre. Esto, con otras palabras, se explicará más adelante.

El sacrificio puede ser, en tercer lugar, y por último, de comunión. Del hebreo zebah, que significa cualquier sacrificio sangriento que incluya una comida religiosa, o shelamin, que significa sacrificio de paz, de salvación, de tributo para restablecer las relaciones con Dios, sacrificio de alianza. En él se busca unirse a la divinidad compartiendo la comida. Desde Egipto hasta Mesoamérica sucedía esto.

En Egipto, el sacrificio cotidiano revestía el carácter de una comida ofrecida a la divinidad, y no se duda en llevar a la boca de la estatua divina el muslo sangrante de la víctima y mancharle los labios con su sangre. (Deiss, 1989, p. 92)

Entre los aztecas sucedía algo similar. Estos daban de comer a los dioses que alimentaban al Universo que daba el sustento a los hombres. Solo así la vida podía continuar. Para los judíos, el sacrificio de comunión era un sacrificio de paz, de salvación, de tributo para restablecer las relaciones con Dios y de Alianza. La víctima, la misma que la del holocausto, excluidas las aves, no se quemaba entera, sino que se dividía en tres partes: una para Dios, otra para el sacerdote y otra para el oferente. A Dios se ofrecía además de la sangre, la grasa, considerada noble (Lv 3, 16-17: “Toda grasa pertenece a Yahvé [...] No comeréis ni grasa, ni sangre”). La comida comunitaria, en la cual el fiel recibía su parte de la víctima, sellaba la comunión 
familiar de Dios con los suyos. Pablo dirá que comer de las víctimas es participar del altar, y participar del altar, es entrar en comunión con Dios (1 Co 10, 18-20).

Este sacrificio tenía un carácter festivo y gozoso. Se decía 'alegrarse delante de Yahvé' (Dt 14, 26). El altar era 'la mesa de Yahvé' (Ex 44, 16; Ml 1, 7, 12) [...] Se depositaban ante él también los panes de la proposición (Lv 24, 5-9), aceite y vino (Nm 15, 1-12), y también sal, condimento necesario para la comida ( Lv 2, 13; Ex 43, 24). Y el buen olor de las viandas, acariciando las narices de Yahvé subía al cielo como 'calmante aroma' (Nm 28, 2; Lv 1, 9. 13). (Deiss, 1989, pp. 95-96)

Entiéndase que no ocurre que Dios coma, sino que la comunión sacrificial expresa la comensalidad, el compartir en la mesa de Dios. Es una comida hecha en su presencia. El altar es una mesa común y el fiel es el invitado de Dios. El carácter festivo y gozoso de esta forma de sacrificio le viene del alimento que, además, se comparte.

Que el hombre sea el invitado de Dios obliga a reconsiderar la definición de sacrificio como introducción de algo profano en el área de lo sagrado para fortalecer el vínculo entre el hombre y Dios. La solemnidad propia del oferente y la violencia sangrienta en las dos primeras formas de sacrificio obnubila la alegría, ese carácter festivo y gozoso que revela el sacrificio de comunión, y que se contiene en todo sacrificio. La consagración alegre del sacrificio solo es posible a partir de ser invitado de Dios. Esto se da, como se sabe, porque, como para la fe yahvista el Universo entero está ya consagrado (Sal 24: "Del Señor es la tierra y cuanto la llena"). A Dios se le presentan las primicias de las cosechas y los primogénitos porque le pertenecen (1 Cr 29, 14: "no se puede ofrecer a Dios nada que no le pertenezca ya. Solo se le entrega lo que de él se ha recibido") (Deiss, 1989). La ofrenda hecha a Dios para rendirle homenaje, entrar en comunicación con Él u obtener un favor de Él (Galot, cit. en Deiss, 1989), viene dada por Él mismo.

El sacrificio nuevo, el del Hijo de Dios en el altar de la Cruz, impide pensar adecuadamente el sacrificio antiguo (Nancy, 2002) (todo sacrificio anterior a aquel). Exceptuando los millones de sacrificios realizados en las periferias o en los repliegues más secretos de Occidente, el sacrificio se ha vuelto una representación, un espectáculo. El sacrificio antiguo no es el de hoy. Ya no se trata del mismo sacrificio, es ambiguo, indistinto, quizás extinto. Frente a esto me parece pertinente plantear una división, más bien una distinción, entre aquel sacrificio antiguo, como el efectuado por Tales, que manda a sacrificar un toro después de aprender la geometría egipcia y circunscribir un triángulo en una circunferencia; y el sacrificio nuevo, ese que "ya no es el mismo" y que ha roto con aquel de manera mimética, como dijera Girard (2002).

Para Jean-Luc Nancy (2002), el asunto del sacrificio no queda claro. ¿Cómo puede estarlo, si hubo, en algún momento, un cambio cualitativo entre lo que él llama "sacrificio antiguo" y "sacrificio nuevo"? Del sacrificio antiguo nada podemos saber si no es a través del prisma del sacrificio nuevo. ¿Cómo entender la inmolación de un toro hecha por Tales simplemente por un descubrimiento geométrico? Actualmente estos dos ámbitos, la ciencia y las prácticas religiosas, se encuentran separadas. Sócrates y Jesús aparecen como los modelos. Tanto uno como otro negaron el valor del sacrificio, autosacrificándose. "Para el uno y el otro, el acontecimiento del sacrificio [...] viene solamente a puntuar y a exponer el proceso y la verdad de una vida que es de parte a parte ella misma el sacrificio" (Nancy, 2002, p. 55). Ya no es posible, a partir de esto, un sacrificio religador con la divinidad, que es unidad. Ya no es posible un sacrificio expiatorio. La vida se llena de "pequeños 
sacrificios", pero en los que ya no va la vida misma. Si el sacrificio antiguo permitía regresar al orden, como nos cuenta Girard, el sacrificio nuevo impone un orden nuevo, un orden espiritual unificando de una vez y para siempre a todos. Este "sacrificio es inseparable del hecho de que él es la verdad desvelada de todos los sacrificios, o del sacrificio en general. No es entonces solamente único, tiene en su unicidad la elevación al principio o a la esencia del sacrificio" (Nancy, 2002, p. 57). El sacrificio antiguo es reproducido en su forma o esquema, pero es reproducido de tal manera que se revela algo totalmente nuevo, una verdad hasta entonces desconocida, convirtiendo a ese sacrificio antiguo en una figura exterior, en algo vano, sin importancia. El sacrificio (nuevo), siendo la superación del sacrificio (antiguo), es el sacrificio propiamente dicho. Y el modelo es Cristo.

El sacrificio nuevo, en la perspectiva recién expuesta, anula la comprensibilidad del sacrificio antiguo, incluso lo niega, lo sacrifica consigo, pues recuerda que solo Dios es quien puede llevar a cabo este sacrificio, esta consagración. El sacrificio de Cristo no encaja directamente con ninguna de las categorías sacrificiales antiguas, pero cada una revela un poco más del misterio (Granados, 2007). Revisado con los ojos puestos en la Escritura cabe decir que:

Es un holocausto, si se considera el carácter irrevocable de la inmolación, ¡aunque aquí la víctima resucita! Es un sacrificio de comunión, si se tiene en cuenta la comida de la Alianza inaugurada en la Cena, ipero aquí la víctima es a su vez el principal oferente! Es una expiación por el pecado, ¡pero aquí la víctima está invadida por la gloria del cielo, está sentada a la derecha del Padre! Así pues, el sacrificio de Cristo es singular, irreductible, trasciende todas las categorías sacrificiales antiguas, realiza la plenitud espiritual del holocausto, del sacrificio de comunión, del sacrificio de expiación. (Deiss, 1989, pp. 98-99)

El sacrificio de Cristo es el sacrificio de sacrificios, el sacrificio del sacrificio en aras de la salvación que se anuncia como mensaje de alegría con el evangelio. Es el modelo del sacrificio, pues revela el deseo y la forma en la que se le limita entre los hombres, como sugiere René Girard (2002). Pero no queda el sacrificio en la Cruz. Se augura en la última Cena. Y esta es un sacrificio de comunión. Este sacrificio tiene, como se dijo, un carácter gozoso y festivo. Así la Cena, que prepara el sacrificio de Cristo en la Cruz, es modelo de todo sacrificio de comunión. La misa es la memoria tanto del último sacrificio, el que explica y resume todos, como la fiesta de la vida.

Las tres formas de acción sacrificial antiguas de distintos pueblos, judíos, griegos, aztecas, por mencionar solo algunos, suponen un interés por el intercambio de bienes, favores y aprecios entre hombres y dioses, o por la expiación de culpas o por el pago de la deuda que tienen los hombres con ellos. El sacrificio en el Islam se caracteriza por la entrega en defensa y para expansión de la religión del profeta (Melo, 2008). El interés caracteriza el sacrificio antiguo. El sacrificio nuevo lo cancela, pues Dios se abaja a la condición humana. No lo hace para incrementar su gloria. Dios se humilló, negó y ofreció a sí mismo por amor, para la salvación de los hombres. El sacrificio de Jesús para los cristianos obliga a pensar el sacrificio de distinta forma al sacrificio interesado. Jesús se ofrenda como víctima propiciatoria en el Gólgota; se regala, se desprende de sí, se da en prenda de salvación, es decir, es y da un regalo que incluye su humanidad y su divinidad. El sacrificio adquiere una nueva dimensión: se nutre del amor, la humildad y el desinterés. Se vuelve un regalo y así todo regalo adquiere 
el carácter de un sacrificio, un desprendimiento amoroso y humilde que se olvida del yo. Todo regalo significa un sacrificio, si no, ¿qué tipo de regalo sería?

\section{El sacrificio como regalo}

Si hablamos de regalo, este también significa comida o bebida delicada y exquisita. El sacrificio de Jesús se anuncia, en un momento previo a su entrega, como comida y bebida en la última Cena, y se reitera en el sacrificio diario y dominical de la misa como acto del sacerdote, al ofrecer este el cuerpo de Jesús bajo las especies de pan y vino en honor de su Padre. El don o regalo de la entrega se prevé en la inmolación de la víctima, como el sacrificio antiguo, en cuerpo y sangre, no por el fuego abrasador que consume todo en ceniza y humo en el altar, sino por el fuego del estómago, del altar y templo que cada hombre es, y que sintetiza y nutre espiritual y físicamente. Ya no son los dioses los que se deleitan con los olores de la hecatombe, sino el hombre el que al hacer a Dios parte de sí, se hace parte, a su vez, de Dios. Los regalos están vinculados a la vida porque los primeros regalos que se hacen se dan en la familia. Los regalos son, entonces, familiares: estrechan el vínculo vital que une. Así como la Eucaristía llena el espíritu del católico, la comida y la bebida (primeros regalos, pero tan cotidianos que pasan desapercibidos, lo mismo que los sacrificios que los padres hacen por "tener algo que llevarse a la boca") animan la vida familiar cuando la familia se reúne a regalarse el pan.

"Danos hoy el pan de cada día", se repite todos los domingos en misa, fiesta de regocijo y obsequios. Este regocijo se reitera en las fiestas que los países católicos celebran en honor a los santos patronos de ciudades y regiones, donde los pueblos todos se reúnen en la mesa a compartir el pan de ese día. Ahí todos comparten y nadie se guarda para sí el bocado, ni tampoco lo acumula, Es ahí donde se "echa la casa por la ventana". No solo se observa esto en las fiestas patronales. La religiosidad y el sacrificio de las bodas, los bautizos, los cumpleaños y otras celebraciones son innegables. He aquí la diferencia entre los cristianos de los países protestantes y los católicos. Los primeros acumulan, los segundos, no; para los primeros, las fiestas son un despropósito; para los segundos, no. Es como si unos recordaran y otros no, las palabras de su común Sagrada Escritura:

No estén pendientes -dice Jesús- de qué comerán o beberán: ¡no se atormenten! Estas son cosas tras las cuales corren todas las naciones del mundo, pero el Padre de ustedes sabe que ustedes las necesitan. Busquen más bien el Reino, y se les darán también esas cosas. (Lc 12, 29-31)

La gratuidad del sacrificio como regalo se hace "sin esperar recibir nada a cambio":

Cuando des un almuerzo o una comida -recomienda Jesús-, no invites a tus amigos, hermanos, parientes o vecinos ricos, porque ellos a su vez te invitarán a ti y así quedarás compensado. Cuando des un banquete, invita más bien a los pobres, a los inválidos, a los cojos y a los ciegos. ¿Qué suerte para ti si ellos no pueden compensarte! Pues tu recompensa la recibirás en la resurrección de los justos. (Lc 14, 12-14)

Dado lo anterior, puede definirse el sacrificio como la ofrenda (regalo) de algo muy estimado que puede dedicarse a una deidad (en señal de homenaje o expiación), a la patria (a 
los héroes esto se les reconoce) o a alguna persona que se estime más que el ego (el yo, el sí mismo). La gratuidad determina el carácter especial de la ofrenda de algo muy estimado. Se trata de un acto de abnegación y desapego, inspirado por la vehemencia del amor. Tanto el que hace la ofrenda como el que la recibe entran en una relación singularísima y exclusiva. La ofrenda sacrificial es un regalo que se hace y se recibe voluntariamente como muestra de afecto o consideración, de amor. De lo que se trata es de un desprendimiento, de dar la prenda por y para otro, para regalarlo a otro, al prójimo, de no apocar lo que se tiene, de no guardar para sí y para el futuro, de no acumular, de desprenderse (desapegarse) del "bocado" para que otro coma hoy.

La multiplicación que hizo Jesús de los panes y pescados y que se describe en el Evangelio de san Juan (Jn 6, 1-13) es, en sobremanera, consabida. Pero si la "multiplicación" no se interpretara literalmente, sino alegóricamente, sería mucho más impresionante el milagro, considera Carlos González. Es decir, si en lugar de hacer de poco ("cinco panes de cebada y dos pescados"), mucho ("se sentaron los hombres en número de unos cinco mil"), Jesús hubiese "convencido" a sus seguidores de compartir, de desprenderse de lo que traían y dar, regalar, con ello hubiese logrado un milagro y una enseñanza mayores, la del sacrificio como don, como regalo. (Arvizu, Granados, Téllez, 2011, p. 116).

\section{El sacrificio de Abraham}

La ofrenda a Dios crea un vacío tan grande como nos es querido lo que se ofrece. Piénsese en Abraham ofreciendo a su hijo. El verdadero sacrificio de Abraham, en el momento en que oyó a Dios, en el momento en que escuchó la petición del Señor, perdió toda esperanza y toda tranquilidad. Sacrificó su esperanza, la esperanza de que su descendencia se multiplicase como las estrellas, la esperanza de ver a su hijo grande, la esperanza de morir compartiendo con el hijo tanto tiempo esperado. Sacrificó su tranquilidad y la tranquilidad de su mujer, de Sara, ya anciana. Abraham sí sacrificó. En su hijo, en el ser que más amaba, se le iba su vida. Pero no renegó. No huyó cuando escuchó su nombre, más bien contestó: “Aquí estoy”. La suerte estaba echada y obedeció (Granados, 2005).

Kierkegaard habla de un movimiento interno, el movimiento de la fe. Un joven, cualquiera, pudiendo ser uno de nosotros, puede enamorarse de una joven, de una pequeña dama y a la vez aceptar que nunca será su esposa, que nunca estará con él: este es el primer paso del movimiento de la fe, la resignación absoluta. Cuando algo se ve como imposible y se le asume como tal, es porque uno se ha resignado a verlo desde lejos, a recordarlo de por vida; es porque se le ha idealizado, se le ha hecho un ideal inalcanzable. Mas si ese joven lograse dar el salto, dar el siguiente paso, el paso de la fe (y luchara por ser fiel a su creencia), lo imposible se haría posible; el ideal se concretizaría. Así fue como Abraham recuperó a Isaac. Este ya estaba perdido, muerto, ofrecido, pero la fe de Abraham nunca desfalleció. Confió en Dios, en ese Dios sabio, benigno y proveedor. La fe obediente de Abraham salvó a Isaac. Y aquí nos encontramos con una característica propia de la fe. Normalmente se le entiende con vistas a una vida postrera, pero es una manera incompleta de comprenderla. La fe se realiza en esta "vida prestada", aquí y ahora. Si la fe se realiza aquí, en la vida, la ruptura del hombre en alma y cuerpo carece de sentido, pues es el hombre entero el que vive, es el hombre entero el que tiene fe. Lutero (1988), para justificar la contradicción entre el hombre libre y el hombre siervo, recurre a una especie de maniqueísmo: divide al ser humano en alma 
y carne, en interno y externo. Este, el hombre externo, está sujeto a los instintos naturales como a las leyes de los hombres, mientras que aquel es libre por la fe, la fe en Cristo redentor. Algo une a estos dos hombres, a Lutero y a Kierkegaard: la desesperación. Para Lutero, el hombre desesperado lo es por no saber si será uno de los elegidos. Para Kierkegaard, la desesperación es la del hombre que no sabe si alcanzará la fe, que no sabe si podrá dar el salto de la resignación a la fe y que por ello su misión termina siendo la función del poeta, la del genio del recuerdo que narra la hazaña del héroe de la fe, de Abraham. "Y la fe es la pasión más alta del hombre" (Kierkegaard, 1999, p. 136). Es aquí donde entra el sacrificio que supera la desesperación.

Ortega y Gasset le critica a Kierkegaard fundamentar su pensamiento acerca de la fe sobre el cadáver de la razón: "se trata de ese eterno cristiano que no fundamenta su cristianismo en algo positivo, ingenuo, generoso y fresco, sino precisamente en el hecho de que la razón sea algo limitado y trágico" (Ortega y Gasset, 1965, p. 46). Asumo la crítica. Olvídese que la fe es un don divino y volteemos a quien la posee, o a quien pudiese poseerla, a saber, al hombre concreto, que en este caso es Abraham. La razón, si únicamente nos atenemos a ella, nos dejaría llanamente en el ámbito moral: Abraham fue un asesino, aunque no haya completado el homicidio, se le ha exaltado de sobremanera, irracionalmente. El deber de todo padre es amar a sus hijos, y en este caso, a su único hijo. Pero el que Abraham sea un asesino es inaceptable. Es claro que hubo algo más en el proceso. No es posible, entonces, circunscribir su caso al ámbito moral, mejor intentemos visualizar otros dos ámbitos; el de la religión y el de la vida. Ambos se experimentan, y el órgano para ello es el de la sensibilidad. Y así como el gusto, esta también se educa. Una experiencia completa incluye las cuatro capacidades de la sensibilidad. Y no se puede descubrir la alegría, que es una emoción o un sentimiento, del sacrificio si no se involucran todas. Es por eso que resulta importante seguir con este camino e ir más allá, incorporando a la reflexión, que no deja de atender el marco estético propuesto, lo que la Biblia y los teólogos señalan o dicen.

Es cierto que el vacío es irrevocable como en el holocausto, en que la víctima se destruye si se lo ve como recién se ha descrito. El vacío que cava la ofrenda en nuestro interior es el lugar en que Dios viene a nosotros. Es el hueco del alma en espera de Él. La brecha por donde entra, la herida cuya presencia cura. En intercambio con Dios hay llamado de hombre y respuesta suya: perder la vida es salvarla en Él, cargar la cruz es descansar, privarse de algo en el sacrificio es enriquecerse en la vida y en la vida eterna. La comunidad ofrece pan y vino y Dios a su Hijo (Deiss, 1989).

\section{EI sacrificio como fiesta}

La Cena eucarística es el modelo de sacrificio, de acción de gracias y de fiesta. Es acción de gracias, porque sin ella no hay misa. Es sacrificio porque la última Cena es representación profética y memorial de la muerte de Cristo. Y la representación solo es posible porque los signos utilizados (pan, vino, comida) tienen significado. De nuevo el alimento remite al gozo y la fiesta. Dicho significado puede resumirse en la alegría. El pan significa el sustento que debe pedirse todos los días; significa el trabajo cotidiano que arranca a la tierra el sustento con el sudor de la frente; es lo esencial en la comida.

[...] cuando un convidado, al oír hablar a Jesús, quiere expresar su alegría y proclamar la felicidad del banquete del Reino, exclama: “iDichoso el que pueda 
comer pan en el Reino de Dios" (Lc 4, 15). "Se habla en la Sagrada Escritura de pan de la alegría (Qo 9, 7)”. (Deiss, 1989, p. 127)

También se habla del pan de las lágrimas (Sal 80,6), el pan de la angustia (Is 30, 20), el pan de la ceniza (Sal 102, 10), el pan de la maldad y de la ociosidad (Pr 4, 17; 31, 27). Por otro lado, no solo la primera hierba (el pan de las primicias), sino la cosecha entera pertenecían a Dios; no solo la primera hogaza, sino la artesa entera. El vino es bien visto por la Biblia. Forma parte de las alegrías que concede Dios al hombre:

Como la vida es el vino para el hombre, si lo bebes con moderación. ¿Qué es la vida a quien le falta el vino, que ha sido creado para el contento de los hombres? Regocijo del corazón y contento del alma es el vino bebido a tiempo y con medida. (Si 31, 27-28)

La misa no es una comida ordinaria en la que, se sabe bien, se bebe o puede beberse agua, como antes sucedía. Con el tiempo, el vino pasó a formar parte de las ofrendas, y en las libaciones fue símbolo de la amistad, del amor y de la alegría de vivir. La fiesta queda anunciada en los signos. El pan y el vino eucarísticos como ofrendas tienen un simbolismo cósmico. La creación -presente en el pan y en el vino-, "frutos de la tierra", se pone en las manos de Dios, convertida en Cuerpo y Sangre de Cristo. Es ofrenda, también, antropológica: el trabajo del hombre transforma la creación y obtiene el pan y el vino, de modo que se ofrece también el trabajo del hombre convertido en Cristo. También tiene simbolismo histórico: recuerda a Melquisedec que anuncia a Jesús. En la Biblia, la comida significa amistad común, presentada a Dios en la oración. Se crea un lazo o una alianza entre comensales. El sacrificio de Cristo trasciende el sacrificio del holocausto y de redención. Es sacrificio, comida y comida sacrificial, pues el cordero pascual es Cristo. Pablo dice:

La copa de bendición que bendecimos, ¿no es acaso comunión con el cuerpo de Cristo? Y el pan que partimos ¿no es acaso comunión con el Cuerpo de Cristo? Porque aun siendo muchos, un solo pan y un solo cuerpo somos, pues todos participamos de un solo pan. (Co 10, 16-17).

La misa es fiesta porque es afirmación de la vida y la afirmación de la vida es alegre. $\mathrm{Y}$ en las fiestas hay comida y bebida; hay una mesa alrededor de la cual los comensales, reunidos en común unidad, en comunidad, departen, reparten y comparten el pan y el vino, que, en la misa, y antes de ella, son símbolos de Cristo y de la unidad en Cristo de la comunidad. El culto cristiano es continuo porque la vida misma es culto. Cuando los cristianos se encuentran es para celebrar una fiesta. La vida comunicada por Cristo pide expresión y exuberancia. "La fiesta consiste esencialmente en la afirmación exuberante de la vida y exige el contraste con el ritmo diario" (Mateos, 1975, p. 253). Para Mateos, la vida cristiana es testimonio de la unidad y felicidad propia del Reino de Dios. La fiesta realiza el Reino de Dios en la Tierra. Toda fiesta es un sí a la vida, un juicio favorable sobre la existencia y el mundo. La fiesta no nace en el vacío de la vida. Expresa abundancia. La alegría de la fiesta presupone un juicio positivo sobre la existencia. Si nada, pues, vale la pena, es absurdo estar alegre. La fiesta asegura que la vida vale la pena. La fiesta, empero, no es diversión, sino un paréntesis en el tedio. La fiesta brota del amor a la vida y afirma su fuerza; el hombre siente que ha nacido para vivir y gozar. Afirma esto contra la evidencia de la 
muerte. La fiesta expresa solidaridad con el mundo. La alegría que expresa no es la beata ausencia de prueba y dolor, sino la vitalidad exaltada capaz de arrostrar lo difícil, el vigor que carga con las responsabilidades.

Al celebrar en la fiesta la existencia y el mundo, el cristiano católico celebra al Creador, fuente de bien y esperanza. La fiesta es agradecimiento y sacrificio. El trabajo es alienante y servil si no hay creación, como sucede en nuestro tiempo. Frente a él florecen los pasatiempos y los espectáculos. La fiesta no es para esclavos que escapan a la realidad o al vacío. Es la afirmación del mundo y de la vida. Se opone al absurdo y al mundo de hoy. Una fiesta como la de la Virgen de Urkupiña, en Bahía Blanca (Hernández, 2010), o una peregrinación con su respectiva fiesta, como la que se celebra anualmente desde Corregidora hasta Querétaro, desde el Santuario de la Virgen de El Pueblito hasta el templo de San Francisco, pueden -a ojos de muchas personas- resultar anacrónicas con respecto a la civilización, representada está en los caminos de asfalto y los edificios de oficinas. Sin embargo, ambas festividades más bien muestran que los edificios, los autos, las autopistas y todo lo que enorgullece a la sociedad civilizada, lucen anacrónicos porque están fuera de lugar y de tiempo, del lugar y del tiempo de la fiesta. Mientras la peregrinación celebra la vida, goza y se alegra de la existencia, la civilización apuntala con fuerza su ser absurdo.

La sonrisa nace de la fe, no de la inconsciencia. El mundo no es rosa en todas sus facetas. La fiesta afirma al mundo como es y afirma con ello su bondad, y confirma que vale la pena vivir la vida. Si el cínico o el escéptico o el nihilista o el ateo se ríen, no es porque su realismo sea mayor, sino porque aún no les llega la buena nueva. La fiesta es el brinco que suelta la traba. En la fiesta, con el apoyo y complicidad de los demás, empieza el hombre a ser él mismo La exuberancia es manifestación de riqueza de espíritu: es efusión, rebose y plenitud; de aquí vienen la generosidad y la tendencia al derroche, síntomas de la abundancia interior. La fiesta es un remanso en el ajetreo de lo diario. La caracteriza el contraste con los días laborables, pero no acepta ser su satélite. La fiesta interrumpe el trabajo del hombre para una actividad más alta, el gozo de la vida. Es una actividad libre y señora, no subordinada a ningún otro fin. La fiesta es el anhelo y la afirmación de una vida plena, feliz, erguida en toda su estatura. La fiesta expresa, por tanto, realidades que el hombre vislumbra y anhela: la vida, la libertad, la plenitud. Las tres se comprenden en la paz, que es vida plena, comunicación humana confiada, fácil y espontánea. La fiesta no puede ser individualista, sino que exige y fomenta el calor humano. La fiesta restituye el sano sentido del humor. La fiesta es generosa, es regalo mutuo (Mateos, 1975).

\section{Conclusión}

Se habló en este artículo de la crítica de Ortega y Gasset a Kierkeggard. A favor de este último podríamos mencionar que quizás el pensador danés sí se para en el cadáver de la razón para hablar de la fe, pero no puede ser de otra manera. La razón sin fe ha alcanzado excesos insoportables en la modernidad. Nos ha dejado fuera de la eternidad, de la alegría. Nos ha enviado a mundos anacrónicos de tráfico e inmediatez. Ha abstraído al hombre dejándolo sin nada, sin vida. La fe sola es, empero, incomprensible. Solo fe y razón, en trabajo conjunto, pueden mostrar al hombre de manera más completa. Y en este caso, la razón ha servido para aclarar la sustancia de la fe; yendo más allá de ella, se ha vislumbrado por qué el sacrificio es alegre. Por eso se eligió el camino de la estética o una perspectiva estética; 
a saber, porque esta disciplina integra o suma las capacidades del ser humano, las involucra sin separarlas ni disociarlas, tampoco las confunde.

Se dijo al principio que la estética es el saber de la propia sensibilidad, la teoría de la belleza y la filosofía del arte, en tanto que disciplina filosófica. Explorando ciertos caminos se ha descubierto que el sacrificio, especialmente el nuevo, encierra una alegría que no puede pasarse por alto, ya que se la vive y satisface o cumple con lo que de eterno requiere el ser humano. La modernidad con sus excesos, especialmente con el de inmanencia, nos ha dejado anclados a un mundo en el que nunca hay, en sentido estricto, satisfacción. Es decir, nunca hay cumplimiento, pues el carácter finito de todo, incluido el del deseo, deja un sinsabor recurrente, difícil de digerir. Se hace necesaria otra experiencia. Esta, además de ser religiosa, es estética, pues se percibe, se imagina, se siente o emociona y se entiende. En todo esto se descubre el sentido o la belleza de ello, especialmente, del sacrificio. Pero no uno cualquiera.

El sacrificio antiguo ya tuvo su tiempo. Se trata de un sacrificio nuevo, el inaugurado por Cristo, el que llena o cumple con las expectativas o los deseos de supervivencia y eternidad, pero siempre en y a partir de este mundo que también requiere de lo suyo. Sacrificar no significa sucumbir, sino regalar. Y regalar, como se dice, es satisfactorio, pues la ofrenda es más enriquecedora que el recibimiento. La emoción no puede no percibirse. La misa se hace el modelo del sacrificio alegre. Esta sí, efectivamente, conmemora la muerte de Cristo, pero insiste en su resurrección. Por eso es posible decir lo siguiente: la misa es acción de gracias. La misa es un sacrificio. La misa es una fiesta. La misa es el modelo de la acción de gracias, del sacrificio y de la fiesta. La fiesta es celebración alegre de la vida. Toda fiesta es sacrificial o es un sacrificio. Y la fiesta y el sacrificio de la misa son acción de gracias (por la vida), holocausto (honra, homenaje, memoria de quien da la vida), expiación (petición de vida) y comunión (con Dios). El sacrificio, así, es alegre. Más aún, si hay algo insacrificable en el sacrificio, eso es la alegría.

\section{Referencias bibliográficas}

Arvizu, A. (2005). Apuntes de estética. Querétaro: Omnes Homines.

Arvizu A., Granados, J., Téllez, R. (2011). Consideraciones de origen sobre la religiosidad en la gastronomía. Fundamentos y supuestos En O. Wingarts Plata, Filosofía, religión y sociedad en la globalización (pp. 106-120). México: UAQ.

Beuchot, M. (2012). Belleza y analogía. Una introducción a la estética. México: San Pablo. Blanco, P. (2007). Estética de bolsillo. Madrid: Palabra.

Deiss, L. (1989). La cena del Señor. Eucaristía de los cristianos (Trad. Concha Munuera). Bilbao: Desclée De Brouwer.

Girard, R. (2002). Veo a Satán caer como el relámpago (Trad. Francisco Díez del Corral). Barcelona: Anagrama.

Granados, J. (2005). Kierkegaard, fe y sacrificio: más allá de la razón. Ponencia en el IX Encuentro Regional de Estudiantes y Pasantes de Filosofía "Los dilemas de la Modernidad", celebrado en Toluca de Lerdo, México (UAEM-CONEFI), 11-14 de octubre.

Granados, J. (2007). El sacrificio. En J. Martínez Contreras y A. Ponce de León (coords.), El saber filosófico 3: Tópicos (pp. 28-34). México: AFM-Siglo XXI.

Hernández, G. (2010). Relatos de vida y religiosidad popular. Origen y sentidos de la fiesta de la Virgen de Urkupiña en Bahía Blanca. Cultura y Religión, 4(2), 147-165. 
Kierkegaard, S. (1999). Temor y temblor. Buenos Aires: Losada.

Lutero, M. (1988). Escritos reformistas de 1520. México: SEP.

Mateos, J. (1975). Cristianos en fiesta. Más allá del cristianismo convencional. Madrid: Cristiandad (Epifanía 21).

Melo, D. (2008). Gloria, sacrificio y martirio en la tradición preislámica y en el islam clásico. Cultura y Religión, 2(1), 31-42.

Nancy, J.L. (2002). Lo insacrificable. En Autor, Un pensamiento finito (pp. 47-82). Barcelona: Anthropos.

Ortega y Gasset, J. (1965). Prólogo para alemanes. En Autor, Obras completas 8 (pp. 15-58). Madrid: Revista de Occidente.

Sahagún Lucas, J. (1999). Fenomenología y filosofía de la religión. Madrid: BAC.

Cómo citar este artículo

Granados, J. (2020). Estética de la alegría del sacrificio. Anacronismo de la modernidad. Revista Cultura \& Religión, 14(1), 13-25. 